\title{
Experimental Testing of the Effects of Fine Particles on the Properties of the Self-Compacting Lightweight Concrete
}

\author{
Sandra Juradin, Goran Baloević, and Alen Harapin \\ University of Split, Faculty of Civil Engineering, Architecture and Geodesy, Matice Hrvatske 15, \\ 21000 Split, Croatia \\ Correspondence should be addressed to Alen Harapin, harapin@gradst.hr
}

Received 19 December 2011; Revised 19 February 2012; Accepted 20 February 2012

Academic Editor: Jin Ping Lu

Copyright (๑) 2012 Sandra Juradin et al. This is an open access article distributed under the Creative Commons Attribution License, which permits unrestricted use, distribution, and reproduction in any medium, provided the original work is properly cited.

The self-compacting lightweight concrete (SCLC) is a combination of the Self compacting concrete (SCC) and the Lightweight concrete. It combines all the good properties of those two materials and is extremely convenient for the construction of buildings that require low mass and do not require high compressive strength, for example restoration works in old structures (e.g., replacement of wooden floors), prefabricated elements that require transportation, and for structures and elements where the concrete surface should be visible. In this paper the effect of the amount of fine particles on the properties of the self-compacting lightweight concrete (SCLC) in the fresh and hardened state was explored. For this purpose, sets of specimens with different combinations of admixtures of silica fume, fly ash, and filler were prepared and tested. Slump flow and flow time of fresh concrete, as well as the dynamic elastic modulus and compressive strength of hardened concrete, were measured at different ages of concrete. The processes of manufacturing and methods of testing are described, as well as the obtained results.

\section{Introduction}

The self-compacting concrete (SCC) can be described as concrete that possess the flowability conditioned by gravity, whereby, when poured into the formwork, it fills all the cavities within the formwork and the need for additional vibration disappears. What makes the SCC different from normal concrete, in its fresh state, is its large deformability and stability which allows pouring in places of dense reinforcement and allows it to completely fill the formwork, without additional vibration and without segregation.

The development of the self-compacting concrete began in the eighties of the last century in Japan $[1,2]$ when the problem of durability of concrete structures was becoming one of the key problems of building with concrete. The material, which until then was considered indestructible and for which it was thought that maintenance was not necessary, began to exhibit a number of shortcomings. In many samples extracted from concrete structures segregation phenomenon at the macrolevel had been observed, and in some places a complete disintegration of the micro structure of concrete $[1,3]$.
Durable concrete structures can be constructed only with good compacting of the concrete which requires a sufficient number of skilled workers. However, the number of skilled workers in the construction industry is constantly decreasing, which led to a gradual decline of the quality of concrete. One solution to achieve the durability of concrete structures, regardless of the quality of the workforce, is the application of the self-compacting concrete that can fill every place and every corner of formwork under only the action of its own weight without the need for vibration. Some experts in the field of concrete technology classified the self-compacting concrete as one of the most important discoveries in the concrete technology over the last few decades [3].

Taking all of these advantages into account, the cost of the more expensive materials can be compensated with a simpler construction method, so the use of the self-compacting concrete is generally cheaper in the end.

Fresh self compacting concrete must have the same basic characteristics as pumped concrete. This means that it must be easy to mold, with no segregation at any level of the grain 
size. The basic requirement for the self compacting concrete is that the paste must have high flowability, but also must be stable. This requirement can be fulfilled using a binder with a high content of fine particles. To achieve high flowability and stability at the same time, particles finer then cement have to be added to the paste. For this purpose the electrofilter $\mathrm{SiO}_{2}$ powder (silica fume), which has an average particle size of several micrometers, is very convenient. Due to its small spherical particles, the silica fume ensures good cohesion and improved resistance to segregation and is effective for the elimination of bleeding. Also, fly ash is very effective in increasing the cohesion and reducing the sensitivity to changes in water quantity. Hydraulic admixtures (such as slag) are already partially included in some cements but can also be added to concrete [1-5].

The mortar itself must also be stable. This requirement is being fulfilled by using the fine aggregate with a sufficient content of grains smaller than $1 \mathrm{~mm}$, which prevents the segregation between the mortar and paste. The other requirement is that the concrete as a whole must be stable and its consistency within certain limits. In terms of content of coarse aggregates there are no special restrictions. High durability is achieved by selecting a low water-cement ratio which is achieved by using superplasticizers, and, if necessary, with the use of additives that change the viscosity (viscosity-modifying additives) $[5,6]$.

Lightweight concretes are concretes whose specific weight does not exceed $1900 \mathrm{~kg} / \mathrm{m}^{3}$. The fact is that in reinforced concrete structures the dead load of the building represents a large part of the total load. The use of lightweight concrete can reduce the weight of the concrete structure, reduce the earthquake forces and the contact stresses in the soil. By reducing the mass of the structure, significant savings in material and construction costs can also be achieved. Also, the lightweight concretes have better insulation properties in terms of thermal insulation and noise insulation. Generally, the lower the strength of the concrete is the better its insulating properties are.

Lightweight concrete can be produced as a lightweight concrete from monograin aggregates, concrete from lightweight aggregates, and cellular concrete. Commonly used aggregates to create a lightweight concrete from lightweight aggregates are the expanded clay, the expanded granulated slag, the expanded perlite or vermiculite, and the expanded polymer materials. These lightweight aggregates have large absorption properties so it is difficult to predict the amount of water required to achieve a specific consistency. Also, lightweight aggregates contain closed cavities, and because of the small volume mass often, during the mixing, rise to the surface causing reverse segregation. This happens only in the unstable concrete. In the stable concrete, in which the amount of water for the preparation is properly selected, segregation is minimal.

Lightweight concretes have a lower modulus of elasticity, higher creeping, and they are more brittle than the plain concrete.

The self-compacting lightweight concrete (SCLC) is a relatively new breakthrough (development) in the field of high performance concrete. It combines all of the good properties of the lightweight concrete with the good properties of the self-compacting concrete. The SCLC is extremely convenient for the construction of buildings that do not require high compressive strengths of concrete, but require low weight. For example these are prefabricated elements that require transportation, and structures and elements where the concrete surface should be visible. It is especially suitable for restoration work in old structures (e.g., replacement of wooden floors) that should not be additionally loaded.

When necessary, improvement of the lightweight concrete strength can be achieved by a combination of the coarse lightweight and the fine stone aggregates. The greatest strength is achieved by the concrete with aggregates of the expanded clay or slag and with the aggregate of the natural crushed stone. The advantage of the expanded clay aggregates is also in the grain shape (spherical shape), which improves the rheological properties of the mixtures and can also affect the increase in the compressive strength [7].

Maghsoudi et al. [7] examined the rheological and mechanical properties of the SCLC which was made with the Leca lightweight aggregate and concluded that using 400 and $500 \mathrm{~kg} / \mathrm{m}^{3}$ of cement produces the SCLC with strength from 20.8 to $28.5 \mathrm{MPa}$. Because of the spherical shape of aggregate, good strength is possible with smaller quantities of cement. Furthermore, they concluded that with the increase of age of the concrete its strength also increases and that the values of the elasticity modulus obtained using 3 different methods are very close to each other. The term which is recommended by the European standard [8] provides significantly more values. The measured strain confirmed that the lightweight concrete is more brittle when compared to the plain concrete.

Hela and Hubertová [9] concluded that, during the mixing of separate factions of the Liapor, the shape of the aggregates' grain (spheres) has a beneficial effect on the mobility and flowability of fresh concrete. However, when lighter and heavier aggregates are mixed together, heavier aggregate tend to significantly sink.

Hence, compared with the self-compacting concrete of normal weight, the self-compacting lightweight concrete shows some specific features that are just the result of the use of the lightweight aggregate.

\section{Experimental Testing of Concrete Mixtures}

2.1. Introduction. In this paper a total of 8 different mixture designs of the SCLC in the fresh and hardened states were made and tested. The intention of the work was to test the influence of the amount of fine particles on the workability and mechanical properties of the lightweight self-compacting concrete in the fresh and hardened state (SCLC). The slump flow and the V-funnel flow time test of fresh concrete, the dynamic elastic modulus and the compressive strength of hardened concrete, and the influence of different ages were measured.

2.2. The Materials and the Composition of the SCLC. For the purpose of examining the effects of the mixture design on the properties of the SCLC, three groups of specimens, 
TABLE 1: Admixtures' characteristics.

\begin{tabular}{lcc}
\hline Type of admixture & $\begin{array}{c}\text { Specific surface area } \\
\text { according to Blaine } \\
\left(\mathrm{cm}^{2} / \mathrm{g}\right)\end{array}$ & $\begin{array}{c}\text { Specific gravity } \\
\left(\mathrm{g} / \mathrm{cm}^{3}\right)\end{array}$ \\
\hline Fly ash-1 & 5118 & 2,25 \\
Silica fume-2 & $>15000$ & 2,30 \\
Filler-3 & 7891 & 2,45 \\
\hline
\end{tabular}

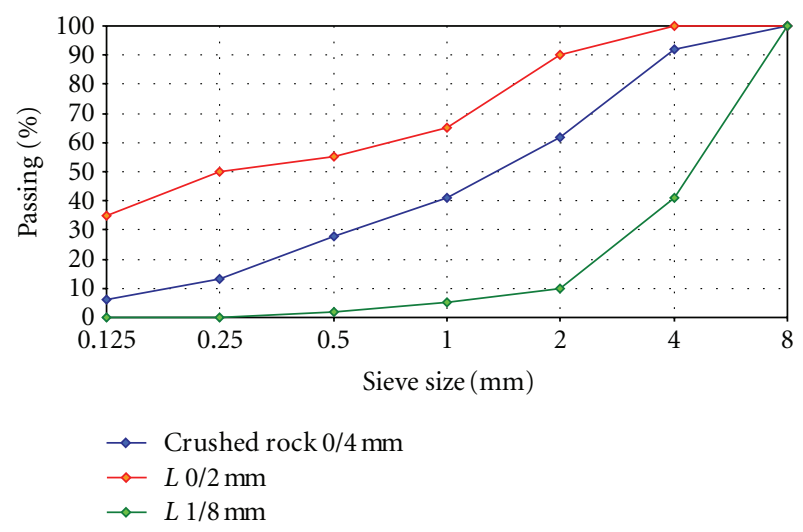

FIGURE 1: The grain size distribution curve of the aggregates.

with a total of eight different mixture designs, were made. In all groups the same cement and superplasticizer were used, while other components were variable. The cement used was CEM I $42.5 R$ with a specific mass density of $3.14 \mathrm{~kg} / \mathrm{dm}^{3}$ and the superplasticizer was the liquid PCE (polycarboxylic acid ether) with a specific density of $1,06 \mathrm{~kg} / \mathrm{dm}^{3}$.

The very light granulated product manufactured by expansion of natural clay-Liapor, was used as the lightweight aggregate. In mixtures, two fractions, the $0 / 2$ (grain size from 0 to $2 \mathrm{~mm}$ ) and the $1 / 8$ (grain size from 1 to $8 \mathrm{~mm}$ ), were used (the grain size distribution is shown in Figure 1).

In some mixtures crushed stone aggregate (crushed limestone) with fractions $0 / 4 \mathrm{~mm}$ (grain size from 0 to $4 \mathrm{~mm}$ ) was also used. The composition and grain size distribution of the crushed limestone is shown in Figure 1.

Silica fume, fly ash, and filler (which was obtained by recycling old concrete) were added to the mixtures. Characteristics of admixtures are given in Table 1.

The composition of each mixture is given in Table 2, and division into test groups is shown below.

Group 1. In the first group of specimens only lightweight aggregate (Liapor) was used as the aggregate. Three groups of mixtures, with labels M1-1, M1-2, and M1-3, were made. Mixture M1-1 had fly ash as an admixture, M1-2 had silica fume, and M1-3 had filler. Mixture M1-3 was, because of the addition of filler, prepared with a greater amount of cement in relation to mixtures M1-1 and M1-2.

Group 2. In the second group of specimens, the combination of Liapor and the limestone crushed aggregate was used as aggregate. Also three groups of mixtures, with labels M2-1,
M2-2, and M2-3, were made. Mixture M2-1 contained fly ash, mixture M2-2 silica fume, and mixture M2-3 contained filler.

A comparison of the masses of $1 \mathrm{~m}^{3}$ of concrete of the first and second group of mixtures (Table 2) shows that the masses of $1 \mathrm{~m}^{3}$ of concrete in the first group were approximately 150 kilograms lesser than the masses of concrete in the second group because of the crushed aggregate.

Group 3. In the third group of specimens, only Liapor was used as the aggregate. Concrete mixtures of the third group have labels M3-1 and M3-2. Concrete mixture M31 contained silica fume and filler in a ratio of $2 / 3-1 / 3$ and concrete mixture M3-2 containing silica fume and filler in a ratio of 1/2-1/2 (volume ratio). Mixtures M3-1 and M3-2 were created to form a group of specimens with mixture M12 (pure silica fume) to examine which combination of these admixtures gives the best performance of concrete in a fresh and a hardened state.

Concrete components that were used in each mixture were measured on a precision scale. Then they were mixed in a mixer for 90 seconds with the addition of water and the superplasticizer. After mixing procedure, concrete was shuffled by hand because the mixer blades could not cover all the material in the vessel, and then the mixer continued to mix for further 90 seconds. After that the concrete was cast in cube-shaped molds $(a=15 \mathrm{~cm})$. After demolding, specimens were cured in water at a temperature of $20 \pm 2^{\circ} \mathrm{C}$. On the day of test specimens were taken out of the water, wiped, and weighed. Before determining the compressive strength, the modulus of elasticity was determined by ultrasound (dynamic modulus). The specimens were tested at $1,3,7$, and 28 days.

\subsection{Test Results of the Fresh SCLC. Immediately after mixing,} the values of slump flow and the $\mathrm{V}$-funnel test were examined (Figure 2(a) and 2(b)).

With the slump-flow method the free deformability and flowability of the SCLC were determined. For the SCC concretes, this value varies from 500 to $700 \mathrm{~mm}$. The main requirement for all concretes (normal, the SCC, and the SCLC) is good stability in fresh condition, that is, volume concentration of the extracted water has to be less than $0,5 \%$.

This method can give a good assessment of whether the phenomena of segregation and separation of the liquid phase of concrete occurs in the concrete.

The deformability of concrete was measured with the method of leakage from a V-funnel. As a good result of leakage of the SCLC, the value between 4 and $10 \mathrm{~s}$ can be taken.

The test results for all mixtures are shown in Table 3

Generally, the following conclusions can be made:

For the 1st group of mixtures,

(i) the value of spreading should be up to $70 \mathrm{~cm}$, so they are within acceptable limits;

(ii) time of leaking should be up to 10 seconds, the result of leak of mixture M1-2 is within that time. The time of leaking of mixtures M1-1 and M1-3 is very long. 


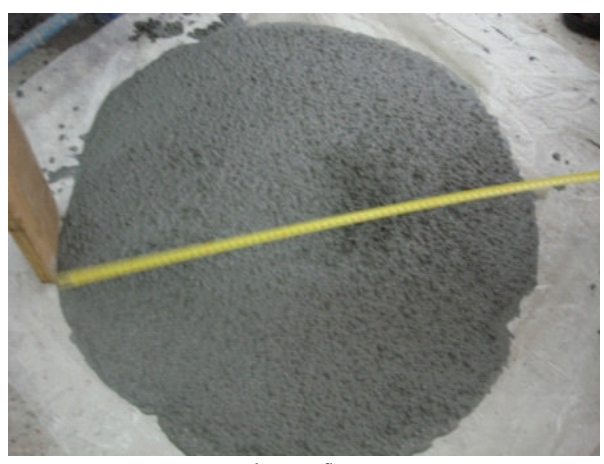

Slump flow

(a)

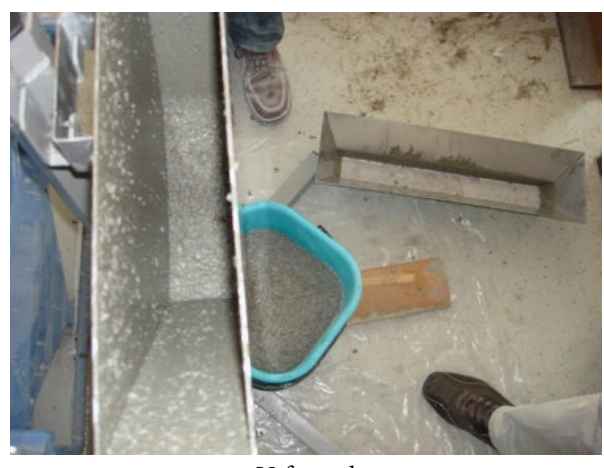

V-funnel

(b)

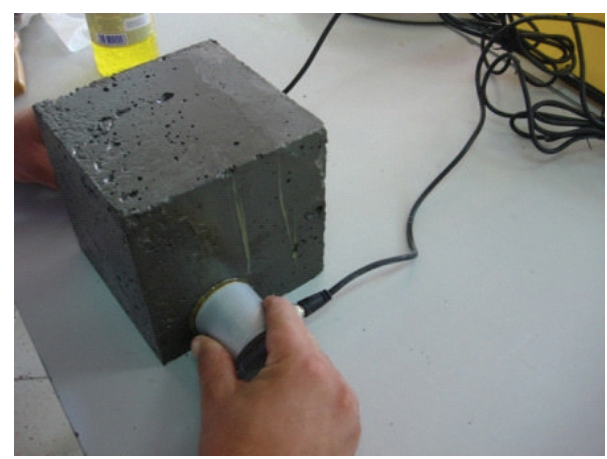

Dynamic modulus of elasticity

(c)

FIGURE 2: Testing of fresh and hardened concrete.

Table 2: Mixture designs.

\begin{tabular}{|c|c|c|c|c|c|c|c|c|}
\hline \multirow{3}{*}{ Concrete compounds } & \multicolumn{8}{|c|}{ Mass $(\mathrm{kg})$ for the $1 \mathrm{~m}^{3}$ of concrete } \\
\hline & \multicolumn{3}{|c|}{$\mathrm{I}$} & \multicolumn{3}{|c|}{ II } & \multicolumn{2}{|c|}{ III } \\
\hline & M1-1 & M1-2 & M1-3 & M2-1 & M2-2 & M2-3 & M3-1 & M3-2 \\
\hline Cement & 380 & 380 & 430 & 380 & 380 & 430 & 380 & 380 \\
\hline Water & 185,60 & 185,44 & 172 & 185,60 & 185,44 & 172 & 185,44 & 185,44 \\
\hline Superplasticizer & 6,0 & 6,37 & 6,76 & 6,50 & 6,86 & 7,28 & 7,0 & 7,0 \\
\hline \multicolumn{9}{|l|}{ Aggregate } \\
\hline lightweight aggregate $0-2 \mathrm{~mm}$ & 346,01 & 347,19 & 353,68 & 172,88 & 173,50 & 176,73 & 345,82 & 346,49 \\
\hline lightweight aggregate $1-8 \mathrm{~mm}$ & 444,87 & 446,39 & 454,73 & 444,54 & 446,13 & 454,44 & 444,63 & 445,49 \\
\hline crushed rock aggregate $0-4 \mathrm{~mm}$ & - & - & - & 333,40 & 334,60 & 340,83 & - & - \\
\hline Silica fume & - & 110 & - & - & 110 & - & 75 & 55 \\
\hline Fly ash & 120 & - & - & 120 & - & - & - & - \\
\hline filler & - & - & 90 & - & - & 90 & 45 & 65 \\
\hline TOTAL & 1482,48 & 1475,39 & 1507,17 & 1642,92 & 1636,52 & 1671,27 & 1482,90 & \\
\hline
\end{tabular}

TABLe 3: Slump-flow and V-funnel.

\begin{tabular}{|c|c|c|c|c|c|c|c|c|}
\hline Test & M1-1 & M1-2 & M1-3 & M2-1 & M2-2 & M2-3 & M3-1 & M3-2 \\
\hline Slump-flow [mm] & 660,0 & 680,0 & 670,0 & 700,0 & 730,0 & 680,0 & 710,0 & 700,0 \\
\hline Class SF & SF2 & SF2 & SF2 & SF2 & SF2 & SF2 & SF2 & SF2 \\
\hline V-funnel $[s]$ & 23,0 & 9,6 & 33,0 & 29,0 & 11,0 & 38,0 & 16,0 & 23,0 \\
\hline Class VF & VF2 & VF2 & - & - & VF2 & - & VF2 & VF2 \\
\hline
\end{tabular}




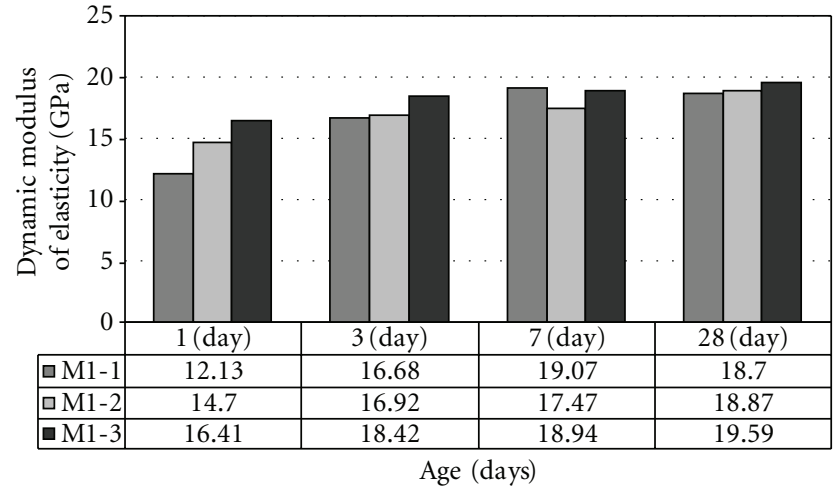

Figure 3: The dynamic modulus of elasticity for the 1st group of specimens.

For the 2nd group of mixtures,

(i) the sizes of spreading are satisfactory; they have greater values than the values of spreading for the first group of mixtures;

(ii) time of leaking was longer than for the mixtures of the first group, especially with M2-1 and M2-3;

(iii) time of leaking of mixture M2-2 was longer than of M1-2, but even though the leak should last less than ten seconds, it is an acceptable value.

For the 3rd group of mixtures,

(i) the sizes of spreading are satisfactory. Spreading values are higher in mixtures M3-1 and M3-2 where the silica fume and the filler were combined in proportions, than in mixture M1-2 where only silica fume was used, or in mixture M1-3 where only filler was used,

(ii) time of leakage is too long. Obviously filler slows the leak because the same phenomenon was observed in mixtures M1-3 and M2-3

These results confirm that the workability of the SCLC and the SCC concrete depends on the quantity of cement and the type and amount of admixtures.

2.4. The Dynamic Modulus of Elasticity. The dynamic modulus of elasticity is determined by measuring the speed of ultrasound waves through the concrete (Figure 2(c)). Speed of longitudinal ultrasonic vibrations that travel through the elastic material is defined by the formula:

$$
\begin{aligned}
v & =\sqrt{\frac{E(1-\mu)}{\rho(1+\mu)(1-2 \mu)}}(\mathrm{km} / \mathrm{s}) \\
\longrightarrow E & =v^{2} \cdot \rho \cdot \frac{(1+\mu)(1-2 \mu)}{(1-\mu)},
\end{aligned}
$$

where $E$ is the dynamic modulus of elasticity, $\rho$ is the density, and $\mu$ is the Poisson's ratio.

The obtained results are shown in Figures 3, 4, and 5.
According to Figure 3, the largest discrepancies in the results of the tests are at the age of samples of 1 day, where at the age of 28 days these values are equalized. The lower value of the dynamic modulus of elasticity in the sample with the fly ash (M1-1) can be explained by the fact that the fly ash activated in the binding only after a prolonged period of time. The best results were achieved in a mixture with fillers, because of larger quantities of cement, which affects the fullness of specimens. Used cement has a characteristic of very high early strength. However, it has to be noted that only one specimen was tested to obtain the results for the 1st day (of hardening). For all other testing days, three specimens of every group and subgroup were prepared and tested. Mean value of all the results of each subgroup is considered relevant.

The dynamic modulus of elasticity for mixture M2-1 (admixture fly ash) has the lowest value for the first day compared to the other two mixtures, but in the next two days, this value increases up by $4,5 \mathrm{GPa}$, while from the 3 rd day to the 28th day it showed growth of around 2,5 GPa, (Figure 4).

It is also evident that the same can be applied for mixture M2-3 (admixture filler); apart from the large increase in the value after the first three days, the value of the dynamic modulus of elasticity is hardly growing, only about $0,5 \mathrm{GPa}$ in the next 25 days.

The dynamic modulus of elasticity for mixture M2-2 (admixture silica fume) has a maximum value after the first day compared to the M2-1 and M2-3, which was not the case for the mixture M1-2 in relation to mixtures M1-1 and M1-3. It is important to note that the dynamic modulus of elasticity for the second group of mixtures, on average, is 3 to $4 \mathrm{GPa}$ higher than in the first group of mixtures, which is a result of the use of the crushed aggregate.

According to Figure 5, mixture M3-1 had the highest modulus of elasticity in each test, that is, the mixture with $2 / 3$ silica and $1 / 3$ filler, although the mixtures in which the filler was used achieved higher values of the dynamic elastic modulus than the mixtures in which only silica was used.

Figure 6 gives an overview of the dynamic modulus of elasticity of all the tested groups, so it can be seen that the type and the amount of the admixtures, the mixing ratio of the admixtures, and the type of aggregate significantly affect the test data.

Admixture Fly Ash. Mixture M2-1 had much better results compared to M1-1, which showed a significant influence of the aggregate type.

Admixture Silica. Mixture M2-2 had the maximum values of the dynamic modulus of elasticity, in which besides Liapor, crushed aggregate was also used as an aggregate. For mixtures M1-2, M3-1, and M3-2 the dynamic modulus had a maximum value for the mixture with the addition of $2 / 3$ silica, and the lowest for the mixture with the addition of $1 / 2$ silica, while the values for the mixtures with $100 \%$ silica were between these two. Exceptions were the values of the modulus at the age of 7 days, where mixture M1-2 had the lowest value (but differences are about $0,6 \mathrm{GPa}$, and this is 


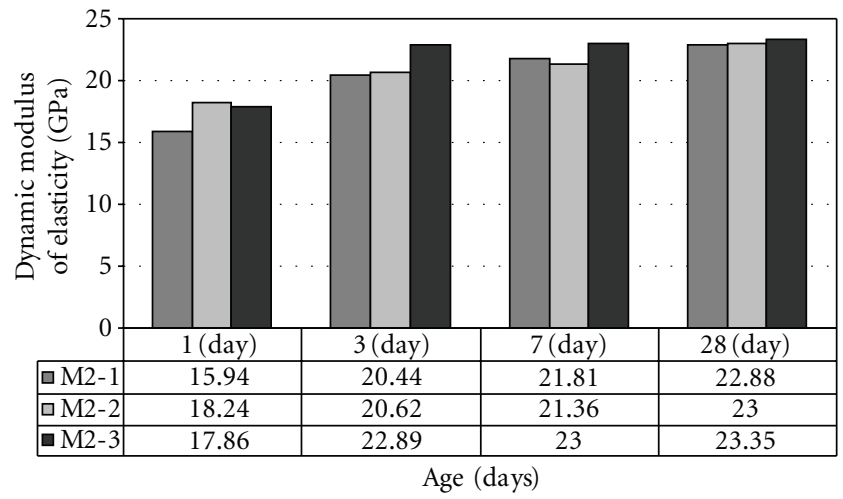

FIGURE 4: The dynamic modulus of elasticity for the 2nd group of specimens.

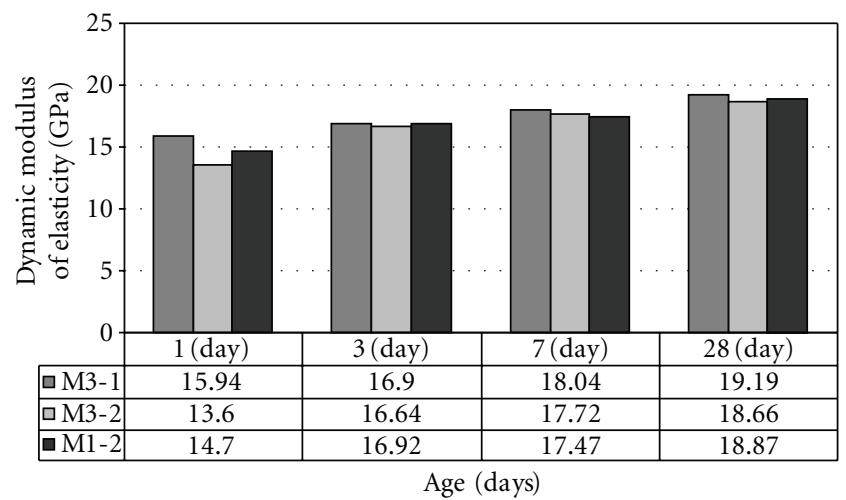

Figure 5: The dynamic modulus of elasticity for the 3rd group of specimens.

irelevant). The value of the dynamic modulus of elasticity after 28 days for mixtures M1-2, M2-2, M3-1, and M3-2 ranged between $4,34 \mathrm{GPa}$.

Admixture Filler. For specimens with filler, the highest value of the dynamic modulus of elasticity was achieved with a mixture of crushed aggregate, M2-3, which was the highest measured value compared to all of the tested specimens. The value of the dynamic modulus of elasticity after 28 days in mixtures M1-3, M2-3, M3-1, and M3-2 ranged between $5,29 \mathrm{GPa}$.

2.5. Results of the Compressive Strength Testing. Compressive strength was determined in the compressive strength testing apparatus in accordance with EN 12390-3. The obtained results are shown in Figures 7, 8, 10, and 11

The highest compressive strength was achieved with mixture M1-2, while M1-1, despite the low initial strength, after 28 days achieved strength close to the strength of M1-3 (Figure 7). It is well known that the silica fume accelerates the development of strength, while fly ash takes some time to be activated. It has to be noted that the strength of the mixtures with filler slightly decreased after seven days.

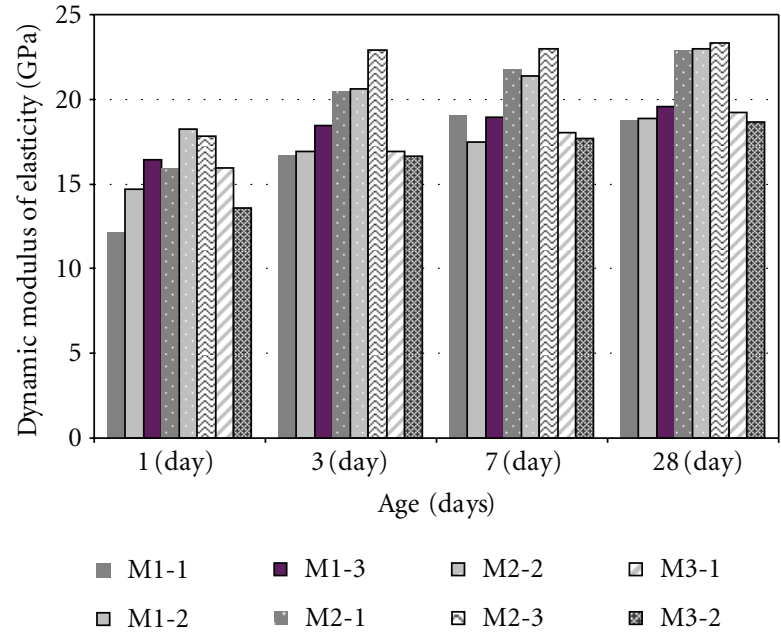

FIGURE 6: The dynamic modulus of elasticity for all tested specimens.

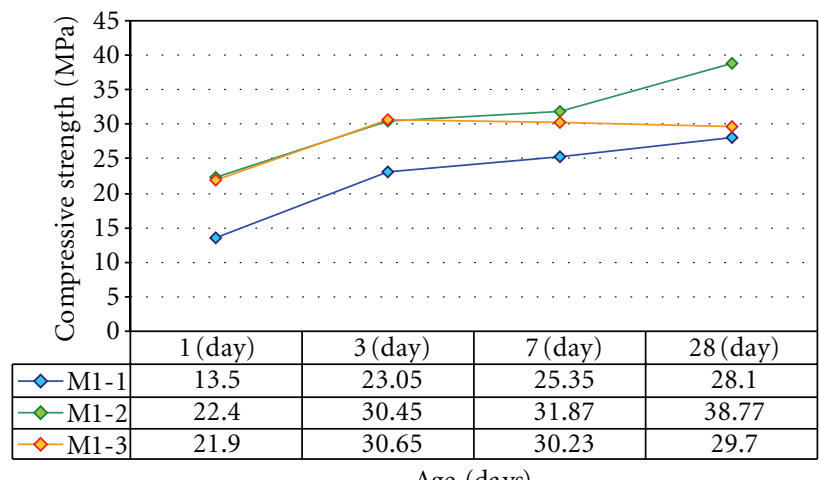

Figure 7: Compressive strength of the 1st group.

Mixtures M2-2 and M2-3 had the highest initial strength, while the strength of mixture M2-1 was significantly lower (Figure 8). The strength of the mixture with filler (M2-3) rapidly reached a maximum value (3rd day), but after that the value decreased and after 28 days had a lower strength than the mixtures with fly ash. Mixture M2-2 (specimen in Figure 9) showed remarkable strength at 28 days of 40,93 MPa.

The strength growth of mixture M3-1 is partially followed with the growth of strength of mixture M3-2, and partially with the growth of strength of mixture M1-2 (Figure 10). The highest compressive strength was achieved with the mixtures with $100 \%$ silica (M1-2), while the mixture with $2 / 3$ silica (M3-1) immediately followed with its strength, despite having had a low initial strength, 5,40 MPa lower than the strength of mixture M1-2. Mixture M3-2 in each test had the lowest strength because it had the highest percentage of filler.

Figure 11 shows the results of all tested groups together, in which it is easy to compare compressive strength of the mixtures for all three groups. 


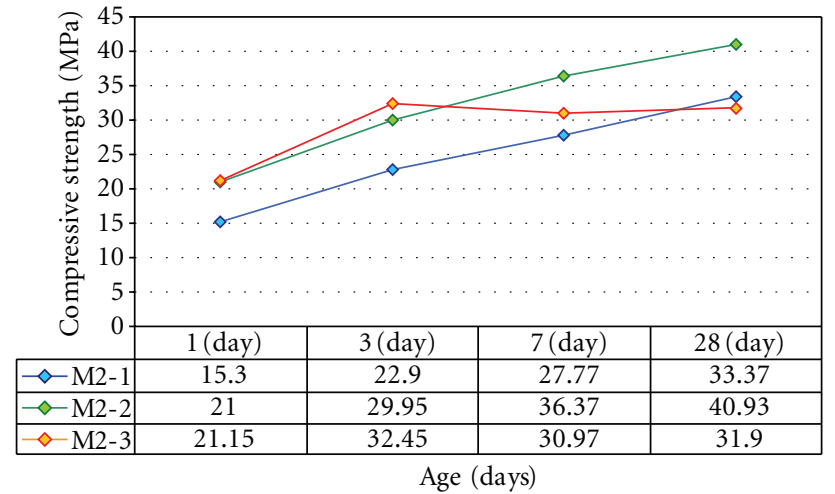

Figure 8: Compressive strength of the 2nd group.

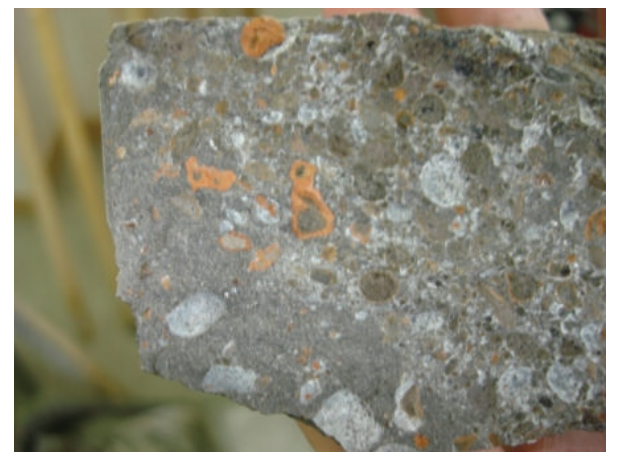

FIgURE 9: Specimen SCLC of the 2nd group after testing.

Admixture Fly Ash. From Figure 11 it is easy to notice that mixture M2-1 had higher strength than mixture M1-1, which was expected.

Admixture Silica Fume. Mixture M2-2 showed the highest compressive strength, compared to the other mixtures with silica, but also compared to the total results. However, it was apparent that mixtures M1-2 and M3-1 also showed very high strength. Mixture M3-2 had low strength compared to the other three mixtures, because of a lower content of silica as an admixture.

Admixture Filler. Mixture M2-3, although containing the expanded clay and the crushed stone aggregate, did not have the highest strength. Mixture M3-1, which had a small content of filler, only one-third, had the greatest strength after 28 days. In that mixture, compared with mixtures of the first two groups, less cement was used. This difference was replaced by silica fume, which proved to be a better option. But strength of the mixture during the first and the second test (1st and 3rd day) was very low and only later showed a significant increase. Mixture M3-2 had similar behavior as mixture M3-1, but not with such a high final strength.

In all of the mixtures in which filler was the only admixture (M1-3 and M2-3) the specimens showed the same trend: an increase in strength in the first three days and then stagnation or even a small decline in strength. This apparent

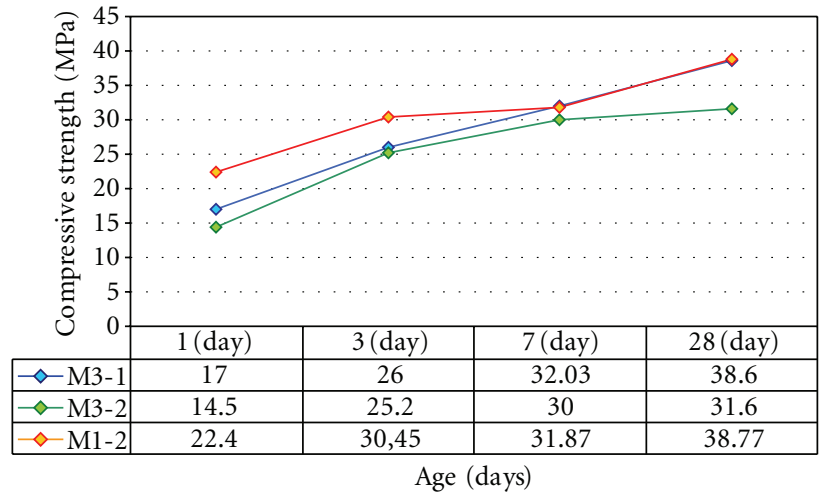

Figure 10: Compressive strength of the 3rd group.

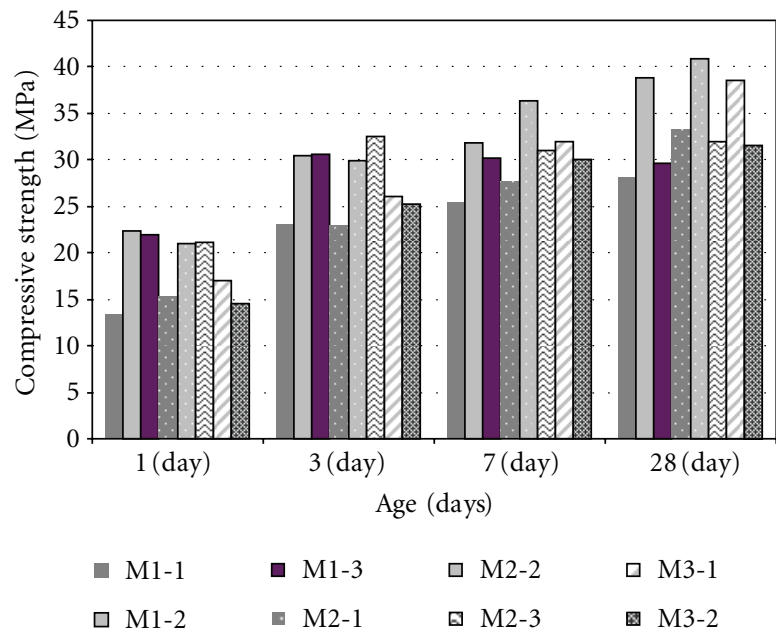

FIGURE 11: Compressive strength of all groups.

increase in strength is caused by the type and quantity of the cement used. The mixtures of the three groups show that this filler as an admixture has to be used in combination with other active admixtures; in this case it was the silica fume (mixtures M3-1 and M3-2). It would be desirable to examine other mixing ratios and different combinations with fly ash. The test results also show that the amount of filler should be less than $50 \%$ of the total admixture (by volume). The test should be extended to a period of at least 90 days.

\section{General Conclusions}

During the design of the concrete mixtures, it is highly important to pay attention to the amount of cement paste in relation to large aggregates. For the self-compacting concrete, the amount of paste is significantly higher than in the standard concrete. The paste serves as a transport agent and allows passage of the aggregates through the narrowest parts inside the formwork and the filling of all the voids. The paste also creates a layer around the aggregate that prevents direct touching between grains of aggregate.

In self-compacting lightweight concretes, this problem is even more emphasized. Lightweight aggregate does not have 
enough starting (initial) energy for the motion of grains in the cement paste. It is therefore very important to balance out the composition of concrete (ratio between the cement, the aggregates, and the inert filler) to produce an easily pourable concrete in a fresh state and a high-quality and compact concrete in a hardened state.

In this work the effect of the amount of fine particles on the characteristics of the self-compacting concrete from lightweight aggregates in fresh and hardened states was explored. The fine particles that were used are fly ash, silica fume, and filler. The ability of spreading and the flow of concrete in the fresh state and the dynamic modulus of elasticity, strength development, and the ultimate strength of the hardened samples were examined. Most of the mixtures were made with only the lightweight aggregate (the expanded clay granules), and in some mixtures the lightweight aggregate was combined with the conventional crushed aggregate.

Based on the achieved results of the tests the following conclusions can be made.

(i) The mixtures that contained silica fume showed the best properties of the self compacting concrete in the fresh state. Those mixtures can be recommended in all cases when lightweight concrete has to be poured in narrow molds or molds with closely spaced reinforcement. Also, these mixtures achieve significant strength. As the silica fume is slightly more expensive than fly ash, and especially the filler, in the case when concrete can be freely placed, it is useful to think about cheaper, but still quality solutions (fly ash, filler).

(ii) In the hardened state, the maximum dynamic modulus of elasticity and compressive strength was achieved by the mixtures that contained the expanded clay and the crushed aggregate, which was expected. Their average weight of those mixtures was greater by $150 \mathrm{~kg}$ per $\mathrm{m}^{3}$ in comparison with other mixtures, but they achieved about $10 \%$ greater strength. Those mixtures can be recommended in cases when higher compressive strength is required and weight of the structure itself is not very important.

(iii) A mixture with additions of $2 / 3$ silica fume and $1 / 3$ of filler showed good results in fresh and hardened states. Since the filler is recycled old concrete, it has a significant economic and environmental impact. Thus, in the future, a strong expansion of precisely this type of concrete is expected.

It is certain that the SCLC will continue to improve in terms of quality, and its use will also increase in the future. Systematic testing of the mixture designs and the mechanical characteristics of the SCLC will create a quality basis for the creation of national and international rules in this area which are still insufficient.

\section{References}

[1] H. Okamura and M. Ouchi, "Self-compacting concrete,",Journal of Advanced Concrete Technology, vol. 1, no. 1, pp. 5-15, 2003.

[2] M. Khrapko, "Self compacting concrete-a solution for technology hungry concrete construction," in Proceedings of the Civil Engineering Testing Conference, New Zealand, September, 2008.
[3] M. Collepardi, "Self-compacting concrete: what is new?" in Proceedings of the 7th International Conference on Superplasticizers and Other Chemical Admixtures in Concrete (CANMET/ACI '03), pp. 1-16, Berlin, Germany, 2003.

[4] N. Štirmer and I. B. Pečur, "Mix design for self-compacting concrete," Gradjevinar, vol. 61, no. 4, pp. 321-329, 2009 (Croatian).

[5] M. Skazlić, R. Rosković, and I. B. Pečur, "Properties of selfcompacting concrete with high fly-ash content," Gradjevinar, vol. 60, no. 11, pp. 945-952, 2008 (Croatian).

[6] N. Spiratos, M. Pagé, N. P. Mailvaganam, V. M. Malhotra, and C. Jolicoeur, Superplasticizers for Concrete: Fundamentals, Technology and Practice, Supplementary Cementing Materials for Sustainable Development, Ottawa, Canada, 2003.

[7] A. A. Maghsoudi, S. Mohamadpour, and M. Maghsoudi, "Mix design and mechanical properties of self compacting light weight concrete," International Journal of Civil Engineering, vol. 9, no. 3, pp. 230-236, 2011.

[8] "The European Guidelines for Self-Compacting Concrete Specification, Production and Use," BIBM, CEMBUREAU, EFCA; EFNARC, ERMCO, May, 2005.

[9] R. Hela and M. Hubertová, "Development of self compacting lightweight concrete using lightweight liapor aggregate, report," 2005, http://www.cideas.cz/free/okno/technicke_listy/2tlven/ 2112-1EN.pdf. 

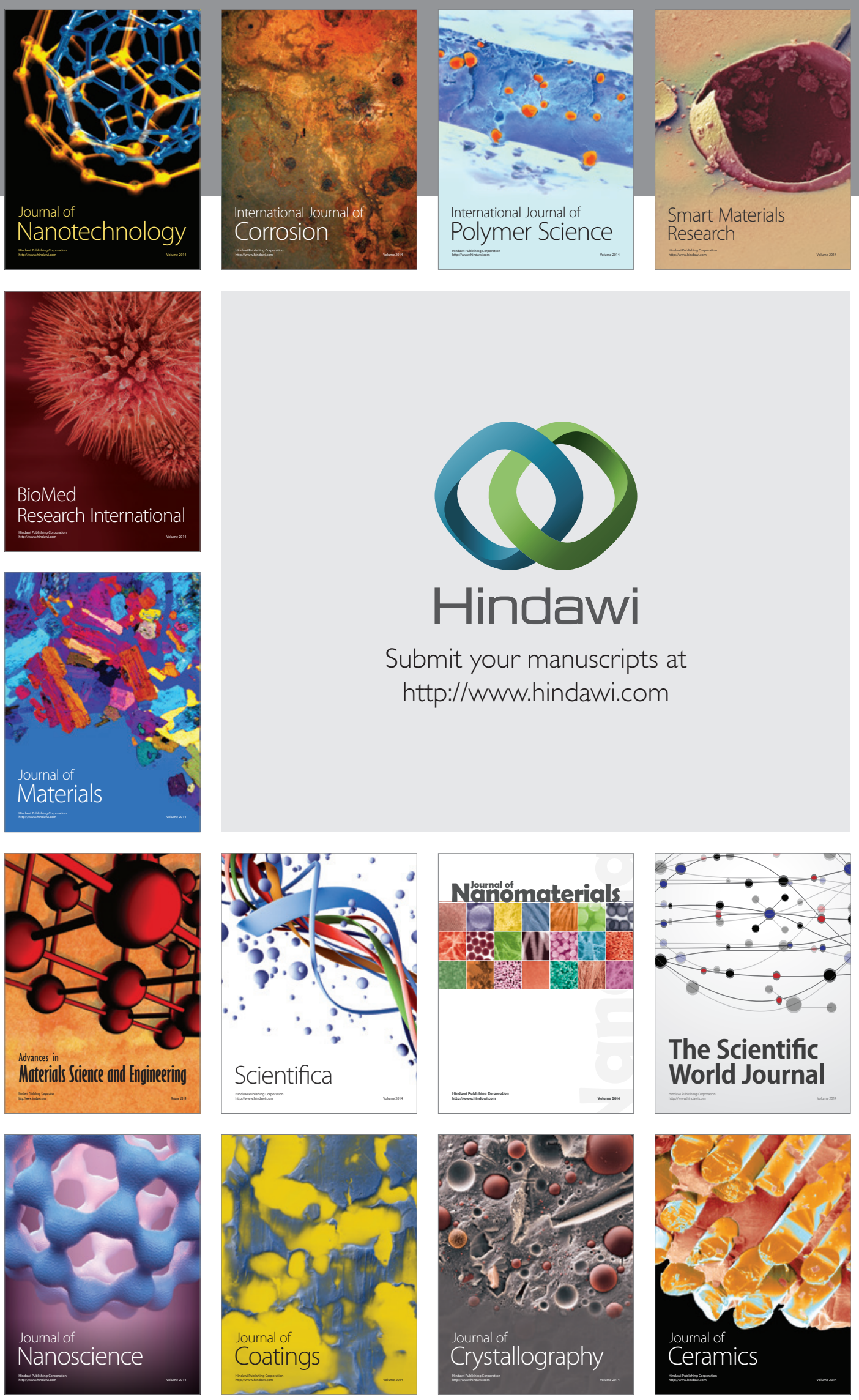

The Scientific World Journal

Submit your manuscripts at

http://www.hindawi.com

\section{World Journal}

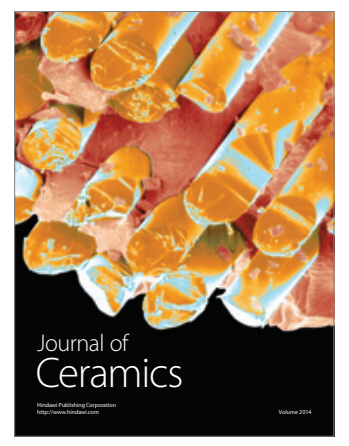

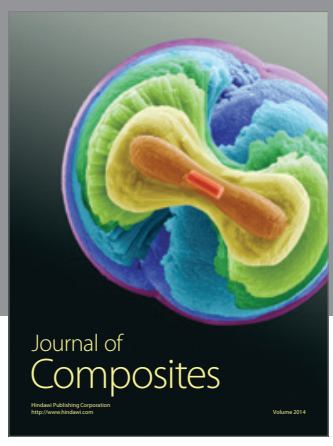
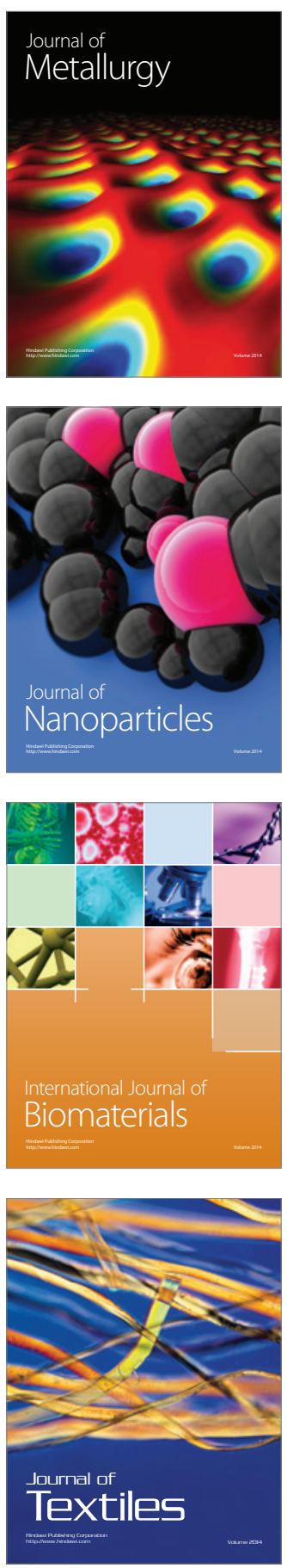